\title{
Synergistic Effects of Relationship Managers' Social Networks on Sales Performance
}

This article integrates relationship marketing and social network perspectives to develop and test a model that links objective sales performance with the informational and cooperative benefits that stem from relationship managers' (RMs') social capital structure (brokerage and density) and relations (formal and informal networks). The authors demonstrate the effect of cross-network and overlap-network synergies on performance. Data about both formal and informal networks of 464 employees, including $101 \mathrm{RMs}$, demonstrate that RMs' performance improves with cross-network synergy when informational benefits from wide-reaching, nonoverlapping ties in the informal network combine with the cooperative benefits of a densely interconnected formal network. In addition, the effects of formal and informal social capital structure on performance increase significantly when RMs have a high degree of network overlap between their formal and informal networks.

Keywords: relationship marketing, social capital, network theory, network synergy, network overlap

$\mathbf{R}$ elationship marketing has wrought permanent changes for the practice of marketing, including an increased focus on the development of long-term customer relationships (Grönroos 1994; Palmatier et al. 2006). Consider, for example, the significant increase in the use of relationship managers (RMs) - boundary-spanning employees who occupy a central role in relationship marketing implementation and are responsible for end-to-end relationships with customers, including communication, sales, and the coordination of interfirm activities (Weitz and Bradford 1999). The importance of RMs continues to increase as sales shift away from products and toward services and solutions (Sheth and Sharma 2008). In their strategic roles, RMs require new competencies to facilitate the alignment of what the seller provides with what the customer demands (Weitz and Bradford 1999). Emerging research based on social network theory has suggested that RMs' internal networks may be especially critical for providing necessary information access and cooperation (Plouffe and Barclay 2007; Steward et al. 2010). Whereas most marketing research has focused on external or interfirm (e.g., supplier, customer) networks, we apply social network theory to understand the effect of RMs' internal

Gabriel R. Gonzalez is Assistant Professor of Marketing, Thunderbird School of Global Management (e-mail: gabriel.gonzalez@thunderbird. edu). Danny P. Claro is Associate Professor of Marketing, Insper Education and Research Institute (e-mail: danny@ insper.edu.br). Robert W. Palmatier is Professor of Marketing and John C. Narver Endowed Chair in Business Administration, Foster School of Business, University of Washington, and Visiting Professor, HEC Paris (e-mail: palmatrw@uw.edu).The authors thank three anonymous $J M$ reviewers for their helpful comments on previous drafts of this article. Christian Homburg served as area editor for this article. social networks on sales performance, thus integrating relationship marketing with social network perspectives.

Relationship managers' membership in social networks generates social capital (Adler and Kwon 2002). As we show in Figure 1, social capital comprises both benefits, such as information and cooperation, and their sources, including the social structure and social relations. Accordingly, to capture an RM's potential to access and leverage information and gain cooperative support from an intrafirm network, we focus on two network structural configurations: brokerage and density. Brokerage provides greater access to and more control over unique, nonoverlapping information that RMs can exchange to achieve performance goals (Burt 1992). With greater density, RMs gain more cooperative support because tightly knit ties help them enforce norms of collaboration through third-party monitoring (Coleman 1988).

However, investigating the effects of RMs' internal social networks is a complex undertaking because RMs are embedded in both formal and informal intrafirm networks. A formal network contains relations based on the firm's prescribed organizational structure, including vertical and horizontal linkages (e.g., superiors, subordinates, peers). It features established procedures and processes. In contrast, an informal network includes relations based on the RM's self-developed, interpersonal ties (e.g., confidants, social linkages). The informal network provides unconventional and novel ways of doing things. Both networks offer necessary benefits, such as information and cooperation, and yet we know relatively little about their interaction, such as that between formal, task-driven structures, as represented in organizational charts, and informal, personalized relational structures (Smith-Doerr and Powell 2005). The dual nature of intrafirm networks thus prompts a worthwhile research 


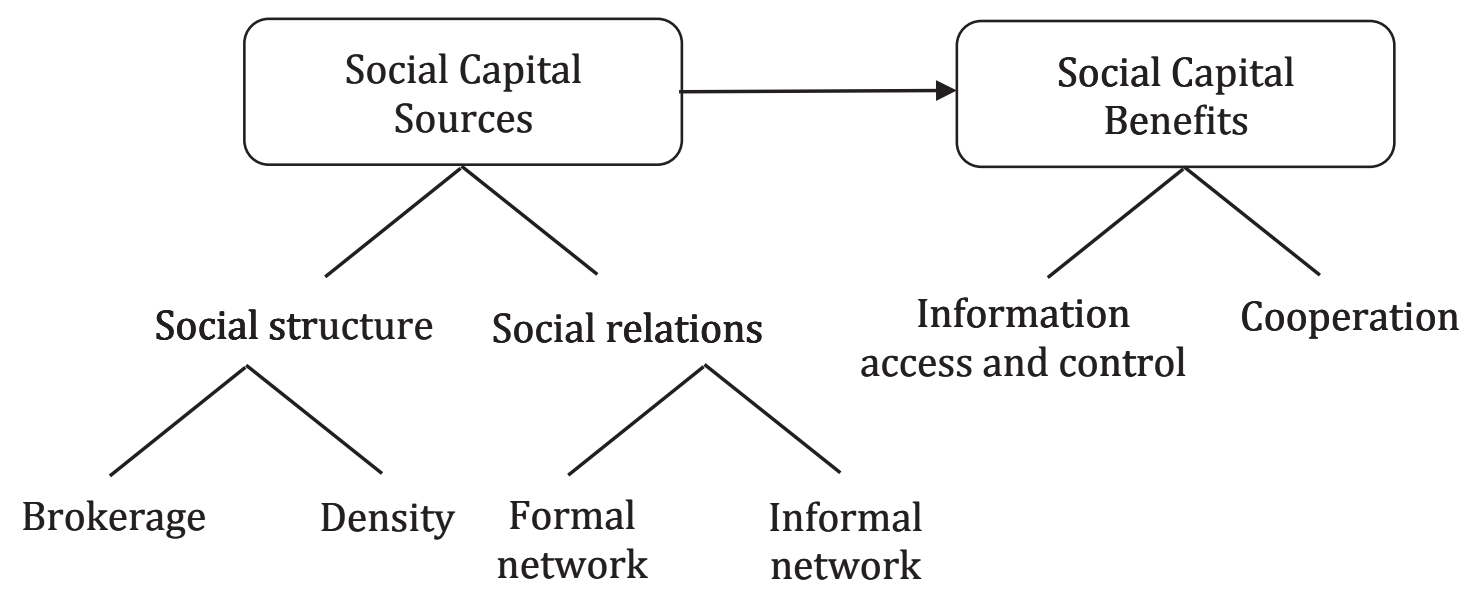

question: what effect does the synergy between formal and informal networks have on RMs' performance?

Network synergy refers to the combination of benefits from multiple networks to produce joint effects that are greater than the sum of their individual effects. It arises in two ways. First, cross-network synergy occurs when information gained from contacts in one network combines with cooperative support gained from contacts in a different network and improves performance. For example, an RM might learn about a new product from an informal contact working in research and development and then successfully sell it to a customer, after gaining assistance from members of his or her formal support network. Second, overlap-network synergy implies the presence of multiple relations (e.g., formal and informal) between RMs. Overlapping ties are strong, so they improve access to unique and private information and encourage reciprocation, which enhances the coordination between parties (Van den Bulte and Wuyts 2007). For example, if an RM discusses a customer problem with a fellow RM who also happens to be a friend (same person in both networks), this coworker might expend extra effort to share private information out of respect for their informal relationship, which then improves the first RM's ability to solve the customer's problem.

We propose and test a conceptual model with a sample of 101 RMs from a supplier of industrial business products. We collected data about their informal networks by surveying 464 employees in the firm; for the formal network data, we turned to the firm's human resource department and used organizational charts that indicate institutionally defined, formal relationships. With a network analysis of both complete networks (i.e., ties involving all employees in the firm), we determine each RM's social capital (brokerage and density). In turn, we integrate the results of these two network analyses with firm-provided control and objective performance data (e.g., sales growth) for each RM to test our empirical model.

This article thus makes three contributions to marketing. First, we theoretically integrate relationship marketing with social capital perspectives to develop a conceptual model that links the informational and cooperative benefits stemming from an RM's formal and informal networks to the RM's objective performance. This study offers a first direct measure of network positions that RMs occupy within their firms and isolates the sources of social capital that drive RM performance. As a result, we introduce new mechanisms to explain how RMs benefit from information and cooperation advantages gained from intrafirm ties. Regarding the social structure, RMs who maintain brokerage positions gain access to and control over nonredundant information from across the firm; RMs in a densely connected group of ties benefit from cooperation due to enforcement and third-party monitoring. With regard to social relations, we identify ways that membership in multiple intrafirm networks (formal and informal) can enhance RM performance.

Second, the empirical results support the premise of cross-network synergy, demonstrating that social capital from multiple networks coalesces to enhance RM performance. The performance-enhancing effects of cross-network synergy are greater than the brokerage and density effects from a single network. Specifically, RM performance improves when the informational benefits gained from informal ties in one network combine with the cooperative benefits attained from formal ties in a different network. In a post hoc analysis, we find that RMs with above-average brokerage (informational mechanism) in their informal network experience $27 \%$ higher sales growth when they also have above-average (vs. below-average) density in their formal network, even though informal network factors have no direct effect on performance.

Third, our results suggest that overlap-network synergy is particularly critical to RM performance because it enhances the effects of three social capital sources: brokerage in the formal network, brokerage in the informal network, and density in the informal network. Overlapping or multipurpose relationships represent "strong" ties that more readily help RMs convert their information and cooperation benefits, gained through the social structure (brokerage and density), into action. The findings reveal enhanced effects 
on RM performance. For example, increasing any one of the three affected social capital sources by one standard deviation improves RM performance by $7 \%$ on average for an RM with average network overlap. This same change in social capital sources increases sales performance by $36 \%$ in the presence of a high degree of network overlap (+1 SD). Thus, RMs' social capital is 29 percentage points more effective for enhancing sales growth when they maintain a high degree of overlap in their informal and formal networks.

\section{RM Performance and Intrafirm Social Capital}

\section{Role of Information and Cooperation in RMs' Performance}

There is increasing recognition that individual boundary spanners occupy a central role in a firm's relationship marketing strategy, representing a bridge between the firm and its customers. For example, relationships between individual salespeople and customers have a greater direct effect on relational behaviors and financial outcomes than do similar relationships spread across multiple members of the firm (Palmatier, Scheer, and Steenkamp 2007). As previously stated, we define RMs as boundary-spanning employees, responsible for end-to-end relationships with customers, including communication, sales, after-sales service, and coordination of interfirm activities (Weitz and Bradford 1999). This definition encompasses a range of job titles, including national account managers, major account managers, key account managers, and global account managers (Davies, Ryals, and Holt 2010). In addition, from a services marketing perspective, this role refers to a "trusted partner" (Sheth and Sharma 2008).

Extant marketing research has addressed the unique role of RMs, suggesting that their position in the firm encompasses two main responsibilities and tasks: (1) to manage and coordinate information inside their firm and (2) to manage internal relationships to gain support for and secure delivery of value to customers (Davies, Ryals, and Holt 2010; Sheth and Sharma 2008; Weitz and Bradford 1999). For example, highly effective RMs navigate their firms' "white spaces" to uncover critical information for delivering customer value and enhancing firm performance (Plouffe and Barclay 2007). In addition, cooperation across independent functional units represents a central task for RMs striving to deliver solutions to customers (Tuli, Kohli, and Bharadwaj 2007). Therefore, an internal or intrafirm network provides RMs with access to critical information and the ability to gain cooperative support, which enhances value creation, relationship quality, and financial performance (Plouffe and Barclay 2007; Üstüner and Godes 2006).

\section{Intrafirm Social Capital}

The emerging body of relationship marketing research has suggested that RMs' social capital, as informed by social network theory, is critical for understanding how they gain access to information and generate cooperative support from other firm members. In Table 1, we summarize key social capital constructs, definitions, and operationaliza- tions. We refer to the social capital structural configuration that provides potential informational benefits as "brokerage." Brokerage captures the extent to which RMs span unconnected network members (Adler and Kwon 2002; Burt 1992) such that this configuration provides access to and control over unique, nonoverlapping information that RMs can exchange to achieve their goals (Burt 1992). Several network characteristics enhance members' access to information, including network heterogeneity (Reagans and Zuckerman 2001) and control over information, such as betweenness centrality (Freeman 1979) and flow centrality (Sparrowe and Liden 2005). However, structural holes best capture the concept of RM brokerage because they encompass both information access and control benefits. A structural hole occurs in a network when an RM's immediate neighbors are neither directly nor indirectly connected through ties involving other third parties (Burt 1992). Spanning a structural hole provides access to nonoverlapping and unique information and increases the RM's ability to engage in information arbitrage because he or she is connected to others who themselves are unconnected (Burt 2005).

Another social capital structural configuration provides cooperation benefits to RMs, namely, "density," or the extent to which an RM's contacts are connected, as reflected in the ratio of actual to possible ties in the RM's network (Coleman 1988). Several network characteristics can produce cooperation benefits, including network density (Swaminathan and Moorman 2009), closeness centrality (Brass and Burkhardt 1993), degree centrality (Ronchetto, Hutt, and Reingen 1989), and tie strength (Wuyts et al. 2004). Highly dense networks, in which people are interconnected so that no behavior goes unnoticed, generate trust and reduce perceived risk through third-party monitoring and "social" enforcement (Coleman 1988). Density leads to cooperation; network members want to build and maintain their reputations for being cooperative because common third parties monitor and discuss those reputations (Burt 2005). Thus, as a result of social norms and pressure, network members adhere to expected standards of behavior and force others to behave in ethical, prescribed, collaborative ways (Seevers, Skinner, and Kelley 2007).

"Network overlap" describes the presence of multiple kinds of relations between actors and exerts effects through dyadic trust and tie strength (Van den Bulte and Wuyts 2007). Network overlap can enhance RMs' information and cooperation benefits. Ties that overlap merge unique and private information from both formal and informal resource pools. Cooperation from overlapping ties is greater because they (1) represent stronger ties, (2) provide more opportunity to evaluate a tie's ability to lend support, (3) afford more ways to provide support, and (4) offer more routes to build positive valence (Van den Bulte and Wuyts 2007).

\section{Conceptual Model and Hypotheses}

Combining insights from social capital theory pertaining to the informational and cooperative benefits gained from brokerage and density with research in marketing that outlines the critical role of information and cooperation in RMs' performance, we derive a compelling rationale to unite social 
TABLE 1

Definitions and Operationalizations of Selected Network Constructs

\begin{tabular}{|c|c|c|c|}
\hline $\begin{array}{l}\text { Network } \\
\text { Constructs }\end{array}$ & Definitions & Operationalizations & $\begin{array}{c}\text { Representative } \\
\text { Publications }\end{array}$ \\
\hline Social capital & $\begin{array}{l}\text { Resources embedded within the } \\
\text { network of relationships possessed } \\
\text { by a person or social unit, compris- } \\
\text { ing both the network and the assets } \\
\text { that the network can mobilize. }\end{array}$ & $\begin{array}{l}\text { Social capital is measured using closure, local } \\
\text { density, structural holes, and the resources of } \\
\text { direct contacts. }\end{array}$ & $\begin{array}{l}\text { Adler and Kwon } \\
(2002) ; \text { Burt (1997); } \\
\text { Coleman (1990) }\end{array}$ \\
\hline $\begin{array}{l}\text { Network overlap } \\
\text { (multiplexity) }\end{array}$ & $\begin{array}{l}\text { The presence of multiple kinds of } \\
\text { relations between actors (e.g., } \\
\text { formal and informal ties). }\end{array}$ & $\begin{array}{l}\text { Network overlap is the proportion of concurrent } \\
\text { ties to the total ties an RM maintains. }\end{array}$ & $\begin{array}{l}\text { Ibarra (1993); Tuli, } \\
\text { Bharadawaj, and } \\
\text { Kohli (2010) }\end{array}$ \\
\hline \multicolumn{4}{|c|}{ Network Constructs That Capture Access and Control of Information } \\
\hline $\begin{array}{l}\text { Brokerage } \\
\text { (structural } \\
\text { holes) }\end{array}$ & $\begin{array}{l}\text { Represents a structural configura- } \\
\text { tion that captures the extent to } \\
\text { which an RM spans unconnected } \\
\text { network members. }\end{array}$ & $\begin{array}{l}\text { Brokerage is measured as } 1-\Sigma_{j}\left[p_{i j}+\Sigma_{q} p_{i q} p_{q j}\right]^{2} \\
q \neq i \neq j \text {, where } i \text { is the RM for which social } \\
\text { capital is measured, j refers to the network } \\
\text { members spanned by } R M i \text {, and } q \text { indicates } \\
\text { other contacts directly or indirectly connected } \\
\text { to the contacts } j \text { and } R M i \text {. }\end{array}$ & $\begin{array}{l}\text { Adler and Kwon } \\
\text { (2002); Burt (1992, } \\
\text { 2004); Reagans, } \\
\text { Zuckerman, and } \\
\text { McEvily (2004); } \\
\text { Uzzi and Spiro (2005) }\end{array}$ \\
\hline $\begin{array}{l}\text { Network } \\
\text { heterogeneity }\end{array}$ & $\begin{array}{l}\text { The degree to which members of a } \\
\text { network represent unique demo- } \\
\text { graphic categories. }\end{array}$ & $\begin{array}{l}\text { Network heterogeneity is the extent to which a } \\
\text { team has achieved a high level of contact } \\
\text { among people who are distant from one } \\
\text { another in a team's demographic characteristic } \\
\text { distribution. }\end{array}$ & $\begin{array}{l}\text { Reagans and } \\
\text { Zuckerman (2001) }\end{array}$ \\
\hline $\begin{array}{l}\text { Betweenness } \\
\text { centrality }\end{array}$ & $\begin{array}{l}\text { Captures the extent to which an } \\
\text { RM is "in the middle of things," } \\
\text { providing both information access } \\
\text { and influence or power. }\end{array}$ & $\begin{array}{l}\text { Betweenness centrality for RMi is measured } \\
\text { as } \Sigma_{\mathrm{j}<\mathrm{k}} g_{\mathrm{jk}}\left(\mathrm{N}_{\mathrm{i}}\right) / \mathrm{g}_{\mathrm{jk}} ; \mathrm{i} \neq \mathrm{j} \neq \mathrm{k} \text {, where } \mathrm{g}_{\mathrm{jk}} \text { is the } \\
\text { number of shortest paths between network } \\
\text { members } \mathrm{j} \text { and } \mathrm{k} \text {, and } \mathrm{g}_{\mathrm{jk}}\left(\mathrm{N}_{\mathrm{i}}\right) \text { is the number of } \\
\text { shortest paths between } \mathrm{j} \text { and } \mathrm{k} \text { that pass } \\
\text { through RMi. The sum of the proportions for } \\
\text { all dyads } \mathrm{j}, \mathrm{k} \text { is RMi's betweenness centrality. }\end{array}$ & $\begin{array}{l}\text { Brass (1984); Brass } \\
\text { and Burckhardt (1993); } \\
\text { Freeman (1979) }\end{array}$ \\
\hline Flow centrality & $\begin{array}{l}\text { A generalization of betweenness } \\
\text { centrality that takes into considera- } \\
\text { tion the notion that network mem- } \\
\text { bers are likely to share information } \\
\text { along multiple paths and not just } \\
\text { the shortest path. }\end{array}$ & $\begin{array}{l}\text { Flow centrality is measured as the extent to } \\
\text { which an RM falls on all paths between any } \\
\text { two pairs of actors and not just the shortest } \\
\text { path. }\end{array}$ & $\begin{array}{l}\text { Freeman, Borgatti, } \\
\text { and White (1991); } \\
\text { Sparrowe and Liden } \\
(2005)\end{array}$ \\
\hline \multicolumn{4}{|c|}{ Network Constructs That Capture Cooperative Support } \\
\hline Density & $\begin{array}{l}\text { The extent to which an RM's con- } \\
\text { tacts are connected. }\end{array}$ & $\begin{array}{l}\text { Density is measured as } L /[g(g-1)] \text {, where } \\
L \text { is the number of directed ties in an RM's } \\
\text { network, and } g \text { is the number of contacts that } \\
\text { an RM has. }\end{array}$ & $\begin{array}{l}\text { Adler and Kwon (2002); } \\
\text { Antia and Frazier } \\
\text { (2001); Swaminathan } \\
\text { and Moorman (2009) }\end{array}$ \\
\hline $\begin{array}{l}\text { Closeness cen- } \\
\text { trality }\end{array}$ & $\begin{array}{l}\text { An RM's ability to quickly receive } \\
\text { (in-closeness) or spread (out- } \\
\text { closeness) assistance by maintain- } \\
\text { ing short distances to other actors } \\
\text { in the network. }\end{array}$ & $\begin{array}{l}\text { Closeness centrality is measured as } 1 /\left[\Sigma_{j} d\left(N_{i} \text {, }\right.\right. \\
\left.\left.N_{j}\right)\right] ; i \neq j \text {, where } d\left(N_{i}, N_{j}\right) \text { is the sum of the } \\
\text { shortest paths between RMi and network } \\
\text { member } j \text {. Closeness centrality is the recipro- } \\
\text { cal of the sum of the shortest paths between } \\
\text { RMi and all network members j. }\end{array}$ & $\begin{array}{l}\text { Brass and Burkhardt } \\
\text { (1993); Ronchetto, } \\
\text { Hutt, and Reingen } \\
\text { (1989); Stam and } \\
\text { Elfring (2008) }\end{array}$ \\
\hline $\begin{array}{l}\text { Degree } \\
\text { centrality }\end{array}$ & $\begin{array}{l}\text { The number of direct ties that an } \\
\text { RM has in the network. }\end{array}$ & $\begin{array}{l}\text { Degree centrality is measured as the extent to } \\
\text { which an RM is directly connected to all other } \\
\text { actors in the network. }\end{array}$ & $\begin{array}{l}\text { Ronchetto, Hutt, and } \\
\text { Reingen (1989); } \\
\text { Palmatier (2008); Tsai } \\
\text { and Ghoshal (1998) }\end{array}$ \\
\hline Tie strength & $\begin{array}{l}\text { The intensity and closeness of a } \\
\text { tie between two actors. }\end{array}$ & $\begin{array}{l}\text { Tie strength is measured as interaction fre- } \\
\text { quency and interpersonal closeness between } \\
\text { an RM and another network member. }\end{array}$ & $\begin{array}{l}\text { Rindfleisch and Moor- } \\
\text { man (2001, 2003); } \\
\text { Steward et al. (2010) }\end{array}$ \\
\hline
\end{tabular}

capital and relationship marketing perspectives. In particular, RMs are embedded in two relevant and distinct networks within firms. Their formal network involves relational ties, according to the firm's prescribed organizational structure and its vertical and horizontal linkages (e.g., superiors, subordinates, peers). The informal network includes relational ties based on RMs' self-developed, interpersonal relationships. The formal network reflects position-to-position ties; the informal network reflects person-to-person ties (Podolny and Baron 1997).

Position-to-position formal relations are largely independent of the person occupying the position, whereas person- 
to-person informal ties depend largely on the specific persons involved. We assume that exchanges in the formal network reflect the explicit responsibilities of each type of organizational position (e.g., superior's responsibility to subordinates) and that any exchange beyond required levels occurs on a strictly voluntary basis. Instead, the terms of exchange in the informal network likely are tacit and voluntary. Organizational researchers acknowledge the important and different roles of these two networks for employee performance. As Krackhardt and Hanson (1993,p. 104) argue, the formal network acts as the "skeleton of a company" that facilitates typical modes of operation and decision making, whereas the informal network acts as the "central nervous system" that provides avenues for adapting to new situations and unexpected problems.

Our conceptual framework in Figure 2 models the effects of brokerage and density in formal and informal networks as positive drivers of RM performance. These sources of social capital have positive influences on a wide range of outcomes because of their informational and cooperative benefits (Coleman 1990; Reagans and McEvily 2003). We generate main effect hypotheses to explicate the mechanisms that underlie the positive effect of brokerage and density on RM performance. In addition, we offer interaction hypotheses consistent with the synergy we expect between formal and informal networks.

\section{Effect of RM Intrafirm Social Capital on RM Performance}

The main benefits of brokerage include access to nonredundant information, earlier access to information, and more control over the diffusion of information (Burt 2005). First, because brokerage places RMs at the crossroads of the flow of information between unconnected knowledge pools, they gain exposure to new ideas and sales opportunities when they trade information during reciprocating transactions (Burt 2004). Second, RMs' bridge-like positions between otherwise unconnected employees give them control over information and its diffusion (Burt 2005). In essence, an $\mathrm{RM}$ high in brokerage is an information hub or the "go-to person" between unconnected groups. Such RMs benefit from unique and early access to information that helps their firms solve customers' problems and generate revenue by increasing the speed at which they learn about and adapt to changing market trends and being first to launch new products (Hutt, Reingen, and Ronchetto 1988; Reagans, Zuckerman, and McEvily 2004). These informational advantages in both formal and informal networks enable RMs with better brokerage positions to outperform RMs with worse brokerage positions (Burt 2004, 2005). This assertion is consistent with the relationship marketing perspective, which indicates that effective RMs control knowledge about their company's competencies and engage in reciprocal exchange strategies with intrafirm members to obtain product inventory, rule and policy concessions, and preferred product modifications (Joshi 2010; Plouffe and Barclay 2007; Weitz and Bradford 1999).

$\mathrm{H}_{1}$ : Brokerage in the (a) formal and (b) informal networks positively affects RM performance.

Density provides RMs with cooperation benefits because people are so interconnected in highly dense or

FIGURE 2

Effect of RMs' Social Capital on RMs' Performance

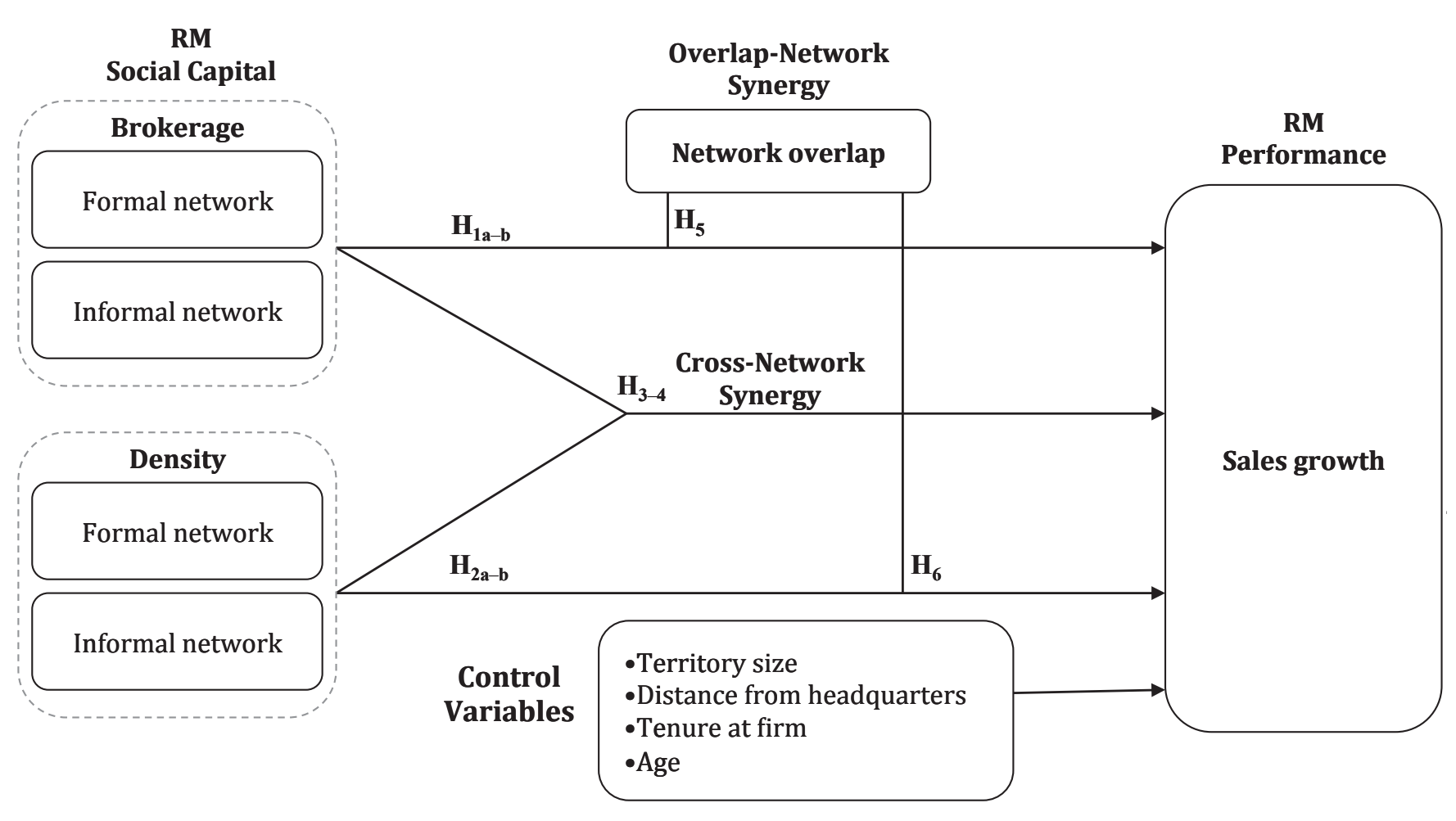


"closed" networks that no behavior goes unnoticed among members (Moran 2005). Thus, densely interconnected networks lead to higher levels of cooperative behaviors through enforcement by third-party monitors (Van den Bulte and Wuyts 2007). As network density increases, network members are subjected to more control because of the reputation effects among network members who work to avoid being labeled negatively (Coleman 1990). Thus, density induces social norms and supports social sanctions that engender a higher degree of mutual obligation, to the point that network members perform favors freely (Moran 2005).

The results include clear role expectations that provide RMs with an ability to complete critical performance tasks in cooperation with coworkers (Moran 2005). That is, RMs in more densely connected networks receive more cooperative support from surrounding network members, which improves their response time, accuracy, and ability to respond to customer problems and opportunities; ultimately, it makes them more effective at increasing customer sales. In marketing, density also creates expectations of cooperation that are critical for the application of disparate expertise during customer solution creation efforts (Üstüner and Godes 2006), provides constraints on unethical behavior (Seevers, Skinner, and Kelley 2007), and produces communal action against those who engage in negative behavior toward another network member (Antia and Frazier 2001).

$\mathrm{H}_{2}$ : Density in the (a) formal and (b) informal networks positively affects RM performance.

\section{Effect of Network Synergies on RM Performance}

Cross-network synergy. By leveraging informational benefits gained from contacts in one network with cooperative support from contacts in a different network, RMs can enhance their performance. We label this synergistic interaction "cross-network synergy." According to Burt (2005, p. 97), "the key to creating value is to put the two together, building closure around valuable bridge relations. Closure is valuable when it spans a structural hole." He goes on to assert that "there is an interaction between brokerage and closure. Performance at the high level of brokerage and closure is more than the sum of the performance expected from high brokerage alone plus high closure alone" (Burt 2005, p. 141). Brokerage improves RMs' intrafirm "vision" across nonredundant areas of the firm, and density increases their ability to get others to provide support (Burt 2005; Coleman 1988, 1990). Combining the benefits of unique information with the required support to solve customer problems, respond to new opportunities, and launch new products should lead to superior RM sales growth performance.

Prior research has supported this positive interaction. Reagans and McEvily (2003) show that productivity gains often result from teams that exhibit closeness among members but sparseness with members outside the team. Similarly, density in combination with structural holes elevates performance (Reagans and Zuckerman 2001). Such studies focus on the effects of combining information and cooperation from contacts in a single network. Logic dictates that the underlying mechanism should produce similar or even greater effects when the information and cooperation come from different networks, because in this case, the knowledge and capabilities tend to be unique and more unrelated across networks than within a single network (Tsai and Ghoshal 1998).

This synergistic interaction also frees RMs from having to manage the trade-offs inherent to brokerage and density. Brokerage provides RMs with information benefits but also makes it difficult to trust those with whom they engage in arbitrage; density results in trust and engenders cooperation but impedes the acquisition of unique information from outside the group (Burt 2005). By bridging structural holes in one network, RMs can identify new opportunities for creating value and then convert that information into higher sales revenue through cooperation with a dense team of trusted members of another network. For example, RMs can leverage information from brokerage in the informal network about future product modifications or alternative postpurchase service options by using their dense formal network to help implement these customer solutions. A dense formal network can translate the information into actions that lead to effective solutions because of its higher levels of cooperative support. Alternatively, from brokerage in the formal network, RMs can acquire information about newly introduced products, alternative product positioning, and new pricing approaches that a dense informal network can leverage. Dense informal networks provide cooperative support that often results in novel implementation processes, which are outside the firm-sanctioned processes.

$\mathrm{H}_{3}$ : The positive effect of brokerage in the informal network on RM performance is enhanced as density increases in the formal network.

$\mathrm{H}_{4}$ : The positive effect of brokerage in the formal network on $\mathrm{RM}$ performance is enhanced as density increases in the informal network.

Overlap-network synergy. To enhance the informational and cooperative benefits gained from brokerage and density, RMs can increase network overlap between their formal and informal contacts. We define this leveraging of social capital benefits as "overlap-network synergy," which occurs when the same network contact appears in both the formal and informal networks, and this convergence results in an advantageous outcome. When network overlap increases, more of the RM's formal contacts (positional ties) are also informal contacts (relational ties), and these overlapped network contacts should be more trusting and relationally motivated to cooperate and share information (Palmatier, Scheer, and Steenkamp 2007). Van den Bulte and Wuyts (2007, p. 33) argue that overlapping ties enhance cooperation through a greater motivation that "stems from experience and affect within the dyad, independently of the larger structure in which the tie is embedded." Similarly, overlapping ties represent stronger relationships, in which reciprocity norms motivate people to share information (Beckman and Haunschild 2002). Simply put, people work harder to help friends than to help coworkers.

Thus, the positive effect of brokerage on RM performance, through access to nonredundant information, earlier access to information, and more control over the diffusion of information, is enhanced when more of an RM's formal 
ties are also friends or informal ties. These overlapping ties are more motivated to assist the RM. Furthermore, greater particularized trust between an RM and his or her overlapping contacts, resulting from increased experience and affect in the dyads, improves performance because they are more likely to reciprocate and exert more effort for the information transfer (Van den Bulte and Wuyts 2007). Extant research has implied that overlapping ties make partners more salient and important, providing greater motivation to communicate (Beckman and Haunschild 2002). They also are more likely to share private information with one another that they might not share with others or that is not part of the public domain (Tuli, Bharadwaj, and Kohli 2010). Consequently, the performance-enhancing benefits that an RM gains from being at an "information crossroads" as a result of his or her brokerage position increase with greater network overlap, because a larger proportion of the contacts in the RM's network are relationally motivated to share unique and private information. In other words, brokerage generates more performance-relevant information when the network contacts are more relationally motivated to help because of their greater network overlap.

$\mathrm{H}_{5}$ : The positive effect of brokerage in the (a) formal and (b) informal networks on RM performance is enhanced as network overlap increases.

In parallel, due to the cooperation of a set of highly interconnected ties who monitor one another's behavior, the positive effect of density on RM performance increases when more of an RM's formal ties are also informally tied to the RM (network overlap). Network overlap increases the contact's relational motivation to help other contacts in the network as well as his or her concern about social sanctions if others perceive him or her to be uncooperative. For example, Tuli, Bharadwaj, and Kohli (2010, p. 38) suggest that network overlap increases relational solidarity, which enables RMs and their contacts to "collaborate and identify avenues for enhancing mutual benefits" and "co-develop offerings that are more likely to be purchased by the customer." The performance-enhancing benefits that RMs gain from being embedded in tightly woven support groups that result from network density thus should grow as network overlap increases, because a larger proportion of the contacts in the RMs' network are relationally motivated to cooperate and worried about being labeled unsupportive.

$\mathrm{H}_{6}$ : The positive effect of density in the (a) formal and (b) informal networks on RM performance is enhanced as network overlap increases.

\section{Research Methodology}

\section{Sample and Data Collection}

The sample for this study consists of RMs in a business-tobusiness firm that distributes and manufactures a broad mix of industrial products (e.g., equipment, chemical supplies, technical services). The supplier sells its private brands of products and distributes other local and global brands. The firm's annual sales of more than $\$ 300$ million are primarily to customers in North and South America, and the account base includes more than 800 customers. Relationship managers' compensation includes a fixed salary and a commission based on sales performance.

This research context is well suited for testing our hypotheses because the RMs are charged with providing integrated solutions that require technical expertise and support from different intrafirm members, and they engage in both relationally complex and transactional exchanges. The majority of RMs in this firm have a technical background, are frequently consulted by customers for technical advice, and bundle an array of products and services to meet customers' needs across the entire sales cycle of their production process. Consequently, RMs' success depends on how well they manage and coordinate information inside their firm, as well as their ability to manage internal relationships to gain support and deliver on their promises to customers. The RMs are primarily men $(80 \%)$, and most act as outside salespeople, without management responsibility (83\%).

We collected data about the informal network through a survey of all 472 firm employees. We administered the network survey (name-generating questionnaire) in the middle of the calendar year, which was also the midpoint of the RM's evaluation period. Prior measures of intrafirm informal ties have centered on several key dimensions, such as trust (Krackhardt and Stern 1988), comfort in confiding sensitive matters (Podolny and Baron 1997), and participation in activities outside work (Lazega and Pattison 1999). In general, network theory identifies two dimensions of informal networks: (1) relationships that assist in work-role performance and involve the exchange of job-related resources and (2) relationships that provide friendship or social support (Ibarra 1993; Podolny and Baron 1997). Paralleling these dimensions, our survey instrument consists of two name-generating questions about respondents' informal ties with coworkers: "Whom would you trust to confide your concerns about work-related issues, and whom would you invite to happy hour after a workday?" Respondents received both questions at the same time and generated a list of intrafirm informal contacts after reading the questions. The response rate of $98.3 \%$ yielded 464 completed questionnaires. Of the $109 \mathrm{RMs}$ in the firm, 101 were eligible for inclusion in the study; 3 RMs did not return the questionnaire, and 5 had not been in their positions long enough for their sales performance to be evaluated.

We relied on organizational charts, policy documents, and consultation with the senior human resource manager of the firm to develop a formal network of the 472 respondents. The formal ties represent superiors, subordinates, and peers with direct formal linkages with each other, in line with prior research that suggests that such networks are based on a 360-degree pattern of task-related ties (Krackhardt 1990; Podolny and Baron 1997). The company also provided the data we used to assess the sales performance of each RM. Finally, the firm provided employee demographic characteristics for use as control variables.

\section{Measurement}

Following extant empirical research, we employed an index for sales growth as an objective, firm-provided outcome 
measure of RM performance (Palmatier, Scheer, and Steenkamp 2007). Sales growth is an appropriate measure of performance because RMs receive annual objectives to increase their sales revenue by acquiring new accounts and growing sales with existing accounts. Sales growth also provides an effective means for comparing the performance of RMs who are responsible for different kinds and sizes of territories and customers. We gathered sales growth figures for the six-month period after the survey data were collected.

To compute the index for sales growth, we divided each RM's six-month sales at time t by six-month sales at time $\mathrm{t}-1$ and then multiplied this figure by 100 . With this approach, sales revenue at time $\mathrm{t}-1$ equals 100 , and relative sales performance is greater than 100 only if sales to customers increase beyond the sales level in $t-1$. For example, if an RM's sales increased by $20 \%$ in time $t$, his or her sales growth index score would be 120; if sales decreased by $20 \%$ in time $\mathrm{t}$, his or her sales growth index score would be 80 . This measure offered a means to avoid the possibility of negative sales growth rates.

The analysis of the formal and informal networks relied on UCINET 6 to calculate the social capital variables for each network, namely, brokerage and density. The measure for brokerage captures the extent to which an RM's network exhibits structural holes (Burt 1992). Following Burt (1992), we used the structural holes variable $(\mathrm{H})$ to assess the lack of redundancy or amount of nonoverlapping information in an RM's network. Nonredundancy is a function of the connection between $\mathrm{RM}_{\mathrm{i}}$ and network member $\mathrm{j}$, measured as the extent to which $\mathrm{j}$ is connected to the other network members $\mathrm{q}$ in $\mathrm{RM}_{\mathrm{i}}$ 's network. Formally, we measure structural holes as follows:

$$
H_{i}=1-\sum_{j}\left[p_{i j}+\sum_{q} p_{i q} p_{q j}\right]^{2} q \neq i, j,
$$

where the squared proportion $\left[\mathrm{p}_{\mathrm{ij}}+\Sigma_{\mathrm{q}} \mathrm{p}_{\mathrm{iq}} \mathrm{p}_{\mathrm{qj}}\right]^{2}$ represents the proportion of $\mathrm{RM}_{\mathrm{i}}$ 's network contacts $\mathrm{q}$ that are directly or indirectly maintained in connection with member $\mathrm{j}$. The focus of the measure is on $\mathrm{RM}_{\mathrm{i}}$ and the lack of structural holes around contacts $\mathrm{j}$. First, the proportion $\mathrm{p}_{\mathrm{ij}}$ captures the extent to which $\mathrm{RM}_{\mathrm{i}}$ is directly connected to $\mathrm{j}$, or the proportion that the tie to $\mathrm{j}$ represents of all the ties that $\mathrm{RM}_{\mathrm{i}}$ maintains. Second, the product $\mathrm{p}_{\mathrm{iq}} \mathrm{p}_{\mathrm{qj}}$ captures the lack of holes around $\mathrm{j}$ as a result of the extent to which $\mathrm{RM}_{\mathrm{i}}$ 's other network members q are connected to contact j. Specifically, the proportion $\mathrm{p}_{\mathrm{iq}}$ is the proportion that the tie to contact $\mathrm{q}$ represents of the total ties that $\mathrm{RM}_{\mathrm{i}}$ maintains. The proportion $\mathrm{p}_{\mathrm{qj}}$ is the proportion that the tie between contact $\mathrm{q}$ and contact $\mathrm{j}$ represents of the total ties that contact q maintains. We estimate the product $\mathrm{p}_{\mathrm{iq}} \mathrm{p}_{\mathrm{qj}}$ for each contact $\mathrm{q}$ and add the sum of the products to $\mathrm{p}_{\mathrm{ij}}$. The squared expression defines the lack of structural holes for contact $\mathrm{j}$ in $\mathrm{RM}_{\mathrm{i}}$ 's immediate network, or the extent to which contacts q reduce $\mathrm{RM}_{\mathrm{i}}$ 's exclusive access to $\mathrm{j}$, and thus the opportunity for brokerage.

When measuring structural holes, the networks surrounding contacts $\mathrm{j}$ can be ignored so that the ties beyond $\mathrm{RM}_{\mathrm{i}}$ 's immediate network have no effect, or they can be included to assess the RM's access to nonoverlapping infor- mation from the larger network (Borgatti, Everett, and Freeman 2002). Because our conceptual framework centers on network-wide information access and control, we chose to include the network ties surrounding an RM's contacts in our estimation of structural holes. The sum of the proportions for all network members $\mathrm{j}$ ranges from 0 to 1 . By subtracting the sum of the proportions from 1, we obtain the structural holes index $\left(\mathrm{H}_{\mathrm{i}}\right)$, indicating the lack of redundancy in $\mathrm{RM}_{\mathrm{i}}$ 's network or access to unique information through nonoverlapping network ties. We multiplied the values by 100 to create a scale from 0 (the RM's network is maximally redundant) to 100 (the RM's network is completely nonredundant). Burt (1992) provides a more detailed description of this measure.

The measure of density captures the number of both incoming ties (i.e., being identified as an informal contact by other employees) and outgoing ties (i.e., informal contacts identified by the RM) for a focal RM. It also includes in-group ties, or the ties that people directly connected with the RM have with one another. To estimate network density (D), we used Borgatti, Everett, and Freeman's (2002) measure, which is the ratio of the number of ties in an RM's network to the maximum possible number of ties:

$$
\mathrm{D}=\frac{\mathrm{L}}{[\mathrm{g}(\mathrm{g}-1)]},
$$

where $\mathrm{L}$ is the number of directed ties in an RM's network, and $\mathrm{g}$ is the number of contacts that an RM has. We again multiplied the values by 100 .

In line with Mitchell's (1969) general conceptualization of multiplexity, network overlap refers to the number of concurrent ties an RM has with contacts in his or her informal and formal networks. To account for differences in network size, we divided the number of concurrent ties by the total number of ties the RM has in both networks (Tuli, Bharadwaj, and Kohli 2010).

Finally, we included several control variables. First, we control for each RM's tenure at the firm in years, to account for other differences in RM relationships not captured by our measures of network position. Second, we control for each RM's territory size in dollars, to acknowledge the potential difficulty of expanding already established sales territories. Third, we control for each RM's distance to headquarters in miles, to account for any differences in ties or communication processes driven by an RM's location. Fourth, we control for RM age using the RM's age in years, to account for potential improvements in RM effectiveness that might result from greater maturity and work experience. The descriptive statistics and correlations for all constructs appear in Table 2.

\section{Results}

\section{Network Structure}

As Figure 3 shows, we mapped 4,903 formal ties and 2,968 informal ties in the firm's networks. Whereas the formal network includes five very dense, loosely interconnected functional groups (Panel A), the informal network indicates 


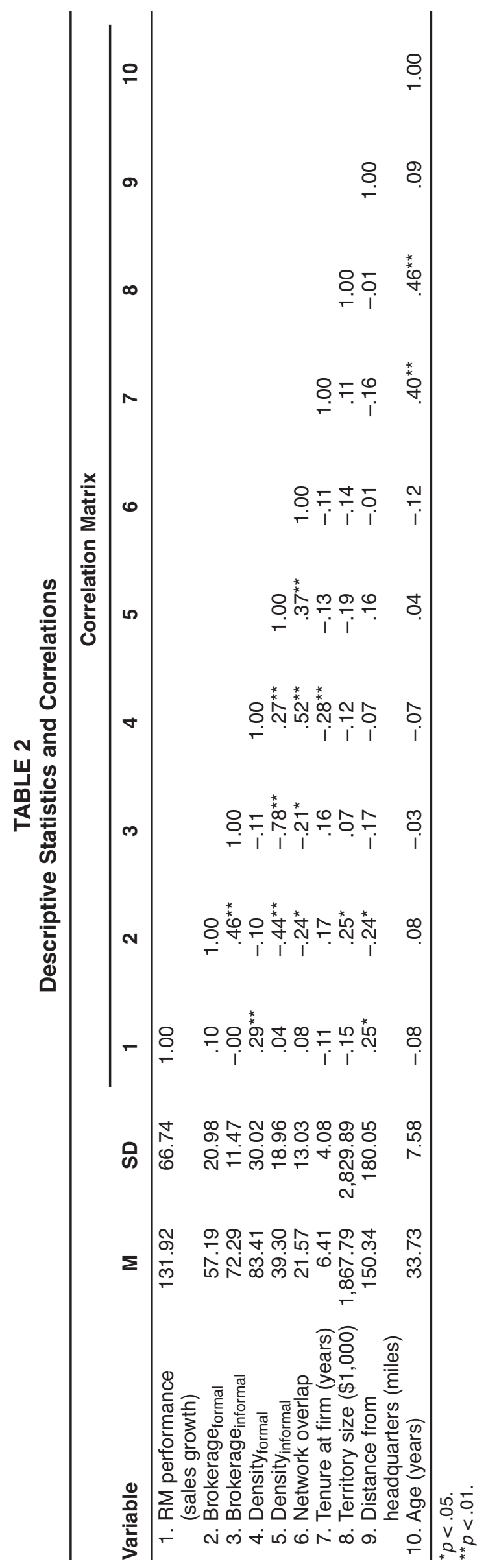


FIGURE 3

The Formal and Informal Networks

\section{A: Formal Network}

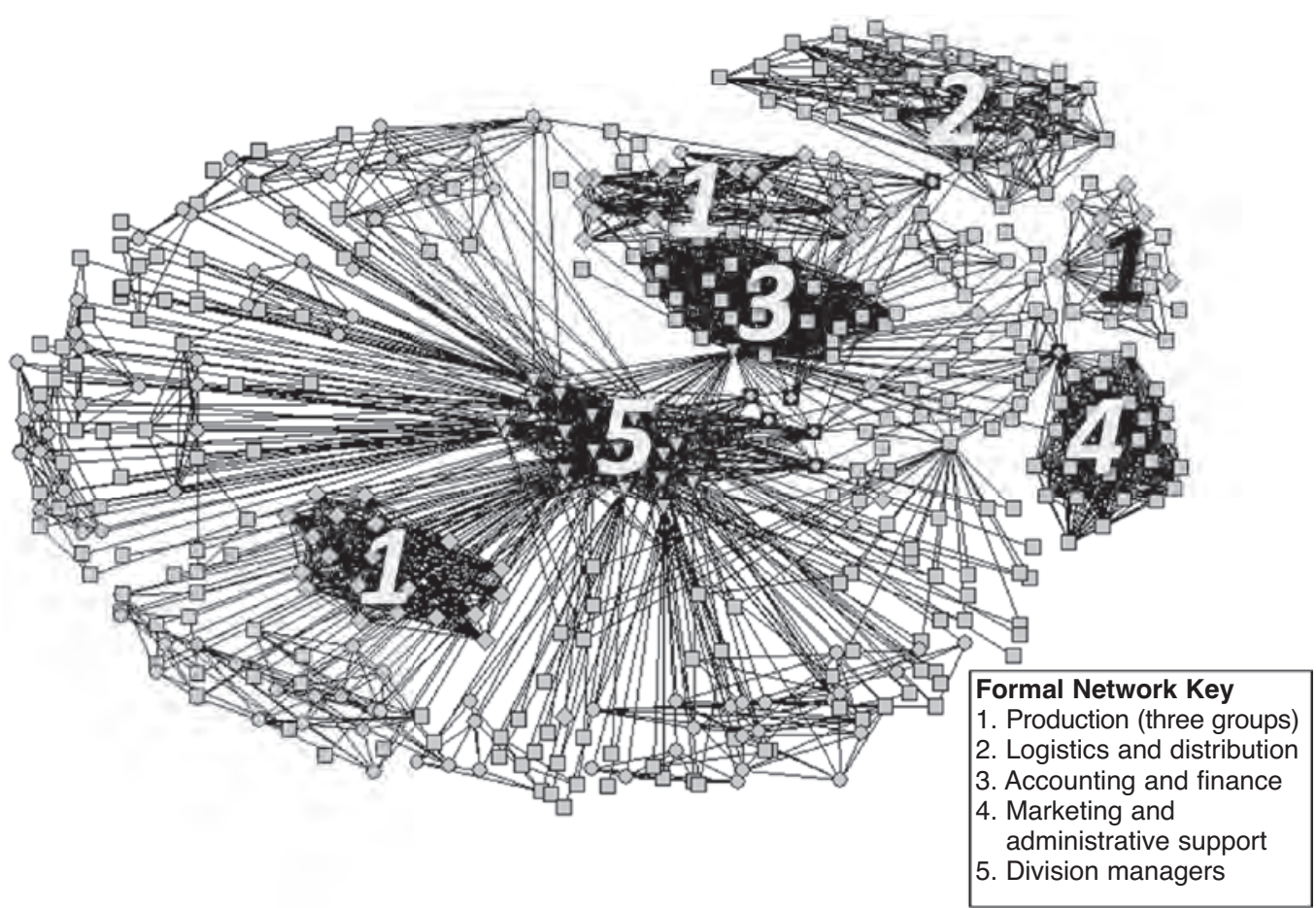

B: Informal Network

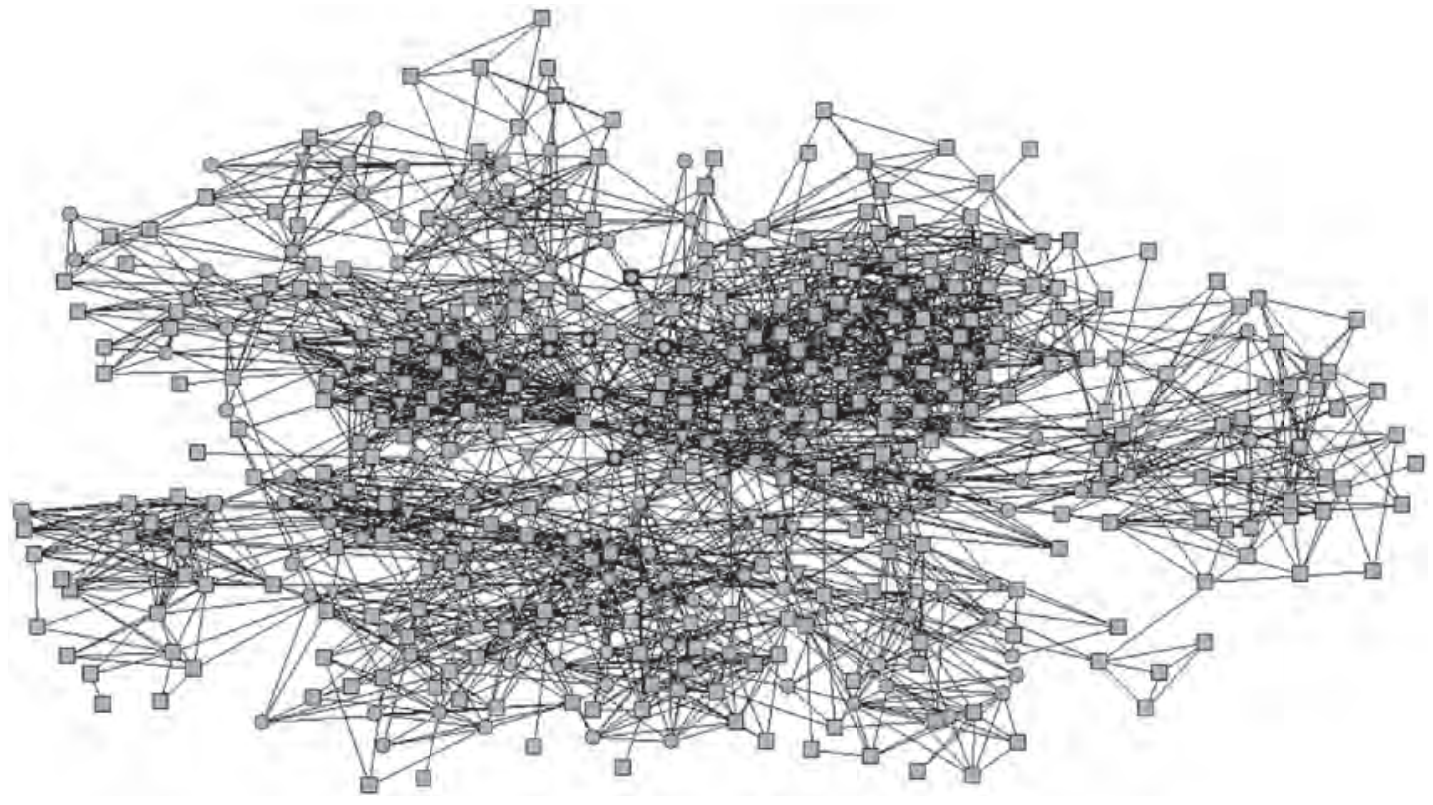

Notes: In both panels, RMs are depicted as circles, division managers as triangles, and all others as squares.

a more unified, somewhat centralized structure, with several isolated groups at the periphery (Panel B). In the informal network, RMs are often in groups at the periphery (depicted as circles in the panels). These two networks differ greatly in structure, and each network demonstrates a high degree of heterogeneity in both brokerage and density, which supports our analysis of the impact of these two measures of social capital on RM performance.

\section{Model Estimation}

We tested our hypotheses using moderated regression analyses, and in Table 3, we summarize the results of the 
TABLE 3

Results: Effect of Intrafirm Network Synergies on Performance

\begin{tabular}{|c|c|c|c|}
\hline \multirow[b]{2}{*}{ Variable } & \multirow[b]{2}{*}{ Hypothesis } & \multicolumn{2}{|c|}{ RM Performance (Sales Growth) } \\
\hline & & Model 1 & Model 2 \\
\hline $\begin{array}{l}\text { Brokerage }_{\text {formal }} \\
\text { Brokerage }_{\text {informal }} \\
\text { Density }_{\text {formal }} \\
\text { Density } \\
\text { informal }\end{array}$ & $\begin{array}{l}\mathrm{H}_{1 \mathrm{a}} \\
\mathrm{H}_{1 \mathrm{~b}} \\
\mathrm{H}_{2 \mathrm{a}} \\
\mathrm{H}_{2 \mathrm{~b}}\end{array}$ & $\begin{aligned} .24 & (2.16)^{\star} \\
-.08 & (-.51) \\
.37 & (3.23)^{\star \star} \\
-.07 & (-.44)\end{aligned}$ & $\begin{aligned} .45 & (2.37)^{\star} \\
-.03 & (-.16) \\
.24 & (1.16) \\
-.03 & (-.15)\end{aligned}$ \\
\hline $\begin{array}{l}\text { Moderating Effects of Cross-Networ } \\
\text { Brokerage }_{\text {informal }} \times \text { density }_{\text {formal }} \\
\text { Brokerage }_{\text {formal }} \times \text { density }_{\text {informal }}\end{array}$ & $\begin{array}{l}\mathrm{H}_{3} \\
\mathrm{H}_{4}\end{array}$ & & $\begin{array}{r}.24(1.95)^{\star} \\
-.17(-1.47)\end{array}$ \\
\hline $\begin{array}{l}\text { Moderating Effects of Overlap-Netwc } \\
\text { Brokerage }_{\text {formal }} \times \text { network overlap } \\
\text { Brokerage }_{\text {informal }} \times \text { network overlap } \\
\text { Density }_{\text {formal }} \times \text { network overlap } \\
\text { Density }_{\text {informal }} \times \text { network overlap }\end{array}$ & $\begin{array}{l}\mathrm{H}_{5 \mathrm{a}} \\
\mathrm{H}_{5 \mathrm{~b}} \\
\mathrm{H}_{6 \mathrm{a}} \\
\mathrm{H}_{6 \mathrm{~b}}\end{array}$ & & $\begin{aligned} .38 & (2.26)^{\star} \\
.40 & (2.01)^{\star} \\
-.12 & (-.73) \\
.56 & (3.01)^{\star \star}\end{aligned}$ \\
\hline $\begin{array}{l}\text { Replication Interactions, Moderators, } \\
\text { Brokerage }_{\text {formal }} \times \text { density }_{\text {formal }} \\
\text { Brokerage }_{\text {informal }} \times \text { density }_{\text {informal }} \\
\text { Network overlap } \\
\text { Tenure at firm (years) } \\
\text { Territory size (\$) } \\
\text { Distance from headquarters (miles) } \\
\text { Age (years) }\end{array}$ & & $\begin{aligned}-.07 & (-.58) \\
.04 & (.39) \\
-.16 & (-1.40) \\
.34 & (3.49)^{\star *} \\
-.06 & (-.53)\end{aligned}$ & $\begin{array}{rr}-.10 & (-.56) \\
-.08 & (-.62) \\
.05 & (.42) \\
.06 & (.53) \\
-.26 & (-2.25)^{\star} \\
.40 & (4.08)^{\star *} \\
-.04 & (-.34)\end{array}$ \\
\hline $\begin{array}{l}\text { R-square } \\
\text { Adjusted R-square } \\
\text { F-statistic } \\
\text { Degrees of freedom }\end{array}$ & & $\begin{array}{c}.23 \\
.16 \\
3.08^{\star \star} \\
(9,91)\end{array}$ & $\begin{array}{c}.36 \\
.23 \\
2.73^{\star \star} \\
(17,83)\end{array}$ \\
\hline
\end{tabular}

${ }^{*} p<.05$.

${ }^{* *} p<.01$.

Notes: The table reports standardized coefficients, with t-values in parentheses. One-tailed significance tests were used for all directional hypotheses.

ordinary least squares regression analyses for two models: main effects only (Model 1) and the final model (Model 2). We mean-centered all the variables in the final model. We assessed the robustness of our approach and measures in several ways. First, the results for the variance inflation factors and condition index ruled out concerns of multicollinearity. Second, an alternative model estimation using Ridge regression yielded identical results to those of ordinary least squares regression. Third, we confirmed that the key constructs significantly differed from one another with paired t-tests.

Our investigation of the direct effect of the RM's social capital on performance yielded surprising results. In Model 1 (main effects only), both brokerage $(\beta=.24, p<.05)$ and density $(\beta=.37, p<.01)$ in an RM's formal network significantly affected performance, but neither aspect of the RM's informal network was significantly related to performance. In Model 2 (interaction effects included), only $\mathrm{H}_{1 \mathrm{a}}$ was significant $(\beta=.45, p<.05)$, and thus, only the effect of RM brokerage in the formal network on performance was significant when we included interactions in the model. These nonsignificant results might indicate that RMs' informal networks are relatively unimportant to their performance, but the picture changes dramatically when we consider our hypothesized network synergies in Model 2. The lack of significant effects for the informal measures of brokerage and density suggests that simply befriending people in the firm offers little direct benefits; such relationships must be combined with other network characteristics to improve performance.

In Model 2, we included both cross-network and overlapnetwork interactions as well as nonhypothesized withinnetwork synergies for the formal and informal networks (brokerage $\times$ density for the same network). Controlling for within-network synergies replicated prior research (Reagans and Zuckerman 2001; Reagans, Zuckerman, and McEvily 2004) and ensured that our results captured the effects of between-network synergies beyond the effects of within-network synergies. Within-network synergy (brokerage $\times$ density for the same network) was not significant for either network, consistent with our premise that knowledge and capabilities tend to be more valuable across different networks than within a single network. In addition, we conducted a post hoc test by adding brokerage $x$ brokerage and density $\times$ density interactions to our model to test whether the same social capital measure across the two networks would provide synergistic benefits. Again, neither interaction was significant, and adding the interactions did not change the significance of any other results. 
Of the two hypothesized cross-network synergies, only one was significant: the results support $\mathrm{H}_{3}$ but reject $\mathrm{H}_{4}$. The positive effect of brokerage informal $\times$ density $_{\text {formal }}(\beta=$ $.24, p<.05)$ on RM performance was significant. In turn, three of the four hypothesized overlap-network synergies received support, in line with $\mathrm{H}_{5 \mathrm{a}}, \mathrm{H}_{5 \mathrm{~b}}$, and $\mathrm{H}_{6 \mathrm{~b}}$ but not $\mathrm{H}_{6 \mathrm{a}}$. The effects of brokerage formal $_{\text {f }} \times$ network overlap $(\beta=.38$, $p<.05)$, brokerage informal $\times$ network overlap $(\beta=.40, p<$ $.05)$, and density $y_{\text {informal }} \times$ network overlap $(\beta=.56, p<.01)$ on RM performance were significant.

Two control variables had significant effects on RM performance. Territory size (\$) revealed a negative association with performance $(\beta=-.26, p<.05)$ : the larger the territory, the more difficult it was for RMs to increase their sales. In addition, the effect of distance on performance was significant and positive $(\beta=.40, p<.01)$ such that RMs located farther from headquarters performed better than those located closer to headquarters.

\section{Graphical Analysis of Interactions}

To explore the nature of the network synergy effects on performance, we conducted both graphical and simple slope analyses (Aiken and West 1991). The graphs in Figure 4 depict the significant interactions from our final model (Model 2). In each graph, high levels of a particular network variable represent values one standard deviation above the mean, and low levels are one standard deviation below the mean. The graph in Panel A shows cross-network synergy, in which brokerage in the informal network interacts with density in the formal network to affect RM performance. For RMs with high brokerage in the informal network (solid line), having more dense formal networks positively drives performance (simple slope analysis results: $\beta=.44, p<.05$ ). The graphs in Panels B-D depict the effects of network-overlap synergy. Panel B shows that RMs with high levels of network overlap (solid line) better leverage the information they gain from greater brokerage in the formal network to improve performance $(\beta=.84, p<$

FIGURE 4

\section{Graphical Analysis of Moderation Effects on RMs' Sales Performance}

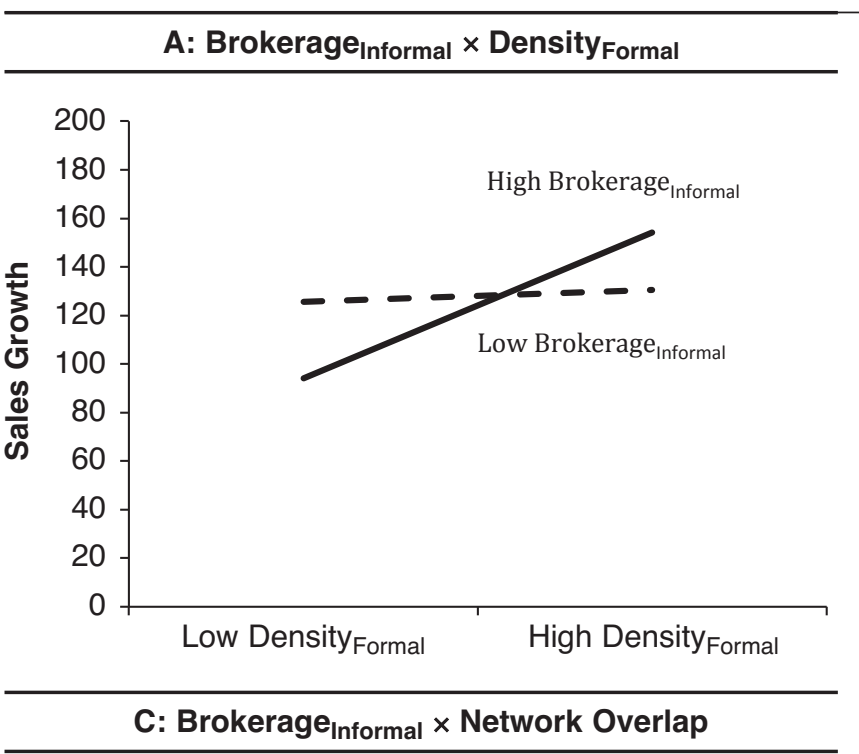

B: Brokerage $\mathrm{Formal}_{\mathrm{F}} \times$ Network Overlap
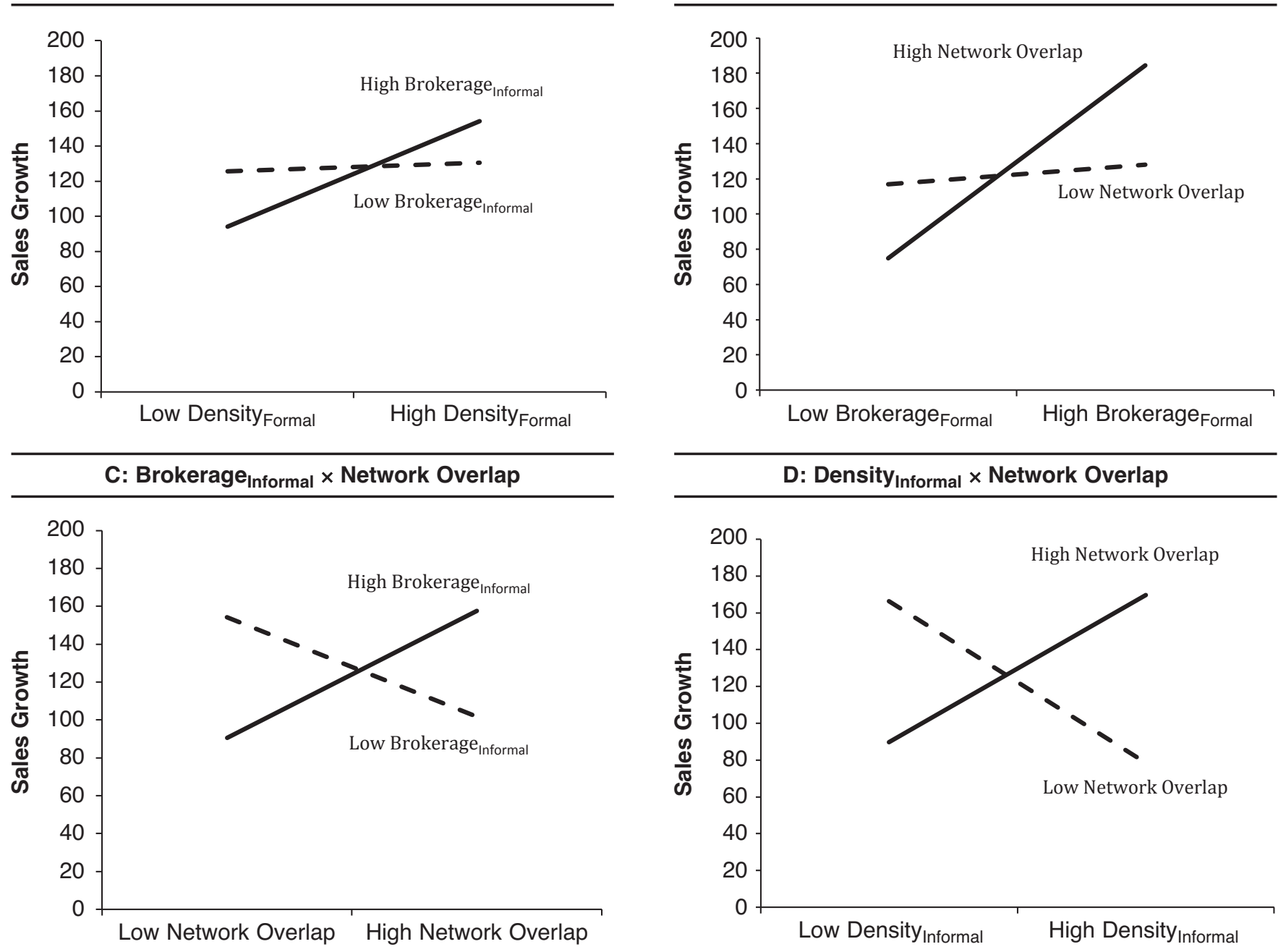

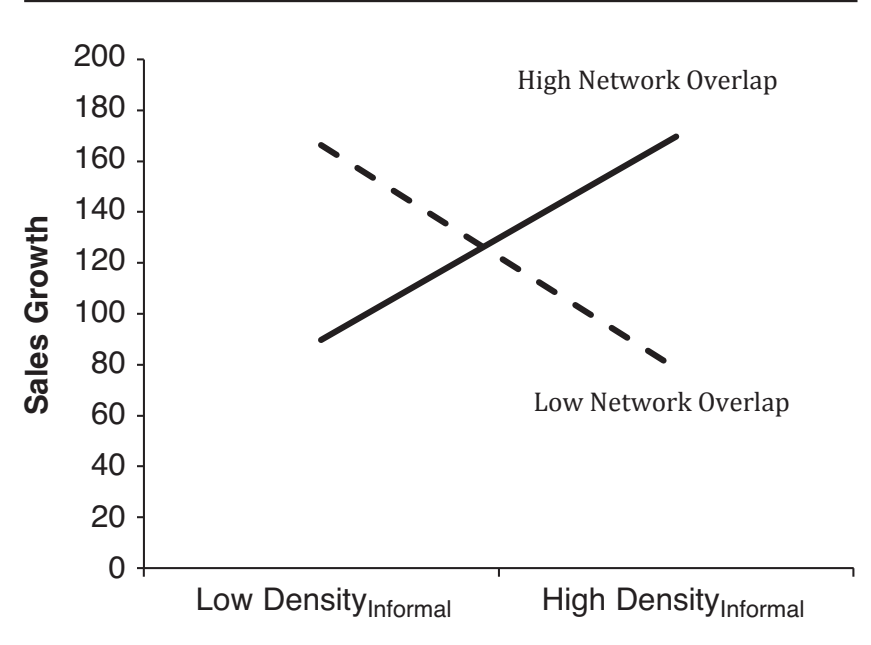


.05). Panel C demonstrates that for RMs with high levels of brokerage in the informal network (solid line), having more overlapping ties increases performance $(\beta=.51, p<.05)$. Panel D shows that more network overlap (solid line) combined with greater density in the informal network augments RM sales performance $(\beta=.59, p<.05)$. Notably, in Panel D, for RMs with low network overlap (dashed line), simple slope analysis demonstrates that a highly dense informal network can be detrimental to performance $(\beta=-$ $.65, p<.05)$. Simple slope analysis also suggests that the interactions involving low levels of brokerage in the informal network (Panels A and C) and low network overlap (Panel B) do not yield statistically significant results; no other condition varies from our expectations.

\section{Sensitivity Analysis}

Alternative measures of social structure capture the information access and cooperation benefits of social capital, but each measure is unique (Table 1). To increase confidence in our conceptual model and the robustness of our findings and to assess the effectiveness of different network measures, we evaluated several alternative models. In each case, we reestimated Models 1 and 2 using a different network structure or dependent variables (Table 4).

First, we investigated another operationalization of brokerage. We replaced structural holes with "betweenness centrality," or the extent to which an actor is "in the middle of things," which provides both information access and control (or power). The betweenness centrality measure used the sum of the probabilities of an RM falling on the shortest path between any two pairs of people for all pairs in the RM's immediate network, which would give the RM both information access and some opportunity to broker the information due to his or her unique (i.e., shortest path) position (Brass 1984). We used UCINET to calculate Freeman's (1979) measure of betweenness centrality. The results were consistent with our previous findings (see Table 4, Models 3a and 3b).

Second, we tested another operationalization of density. We replaced network density with "in-closeness centrality," or the extent to which an RM could receive assistance quickly by maintaining short distances to other actors in the network. We again employed UCINET to calculate Freeman's (1979) measure of in-closeness centrality as the inverse of the sum of the distances between an actor and all other actors in the network. In-closeness describes an RM's centrality in the overall firm network; RMs with high in-closeness scores exhibit shorter distances to all others in the network, resulting in a densely interconnected support network and higher levels of cooperative behaviors through enforcement by thirdparty monitoring (Van den Bulte and Wuyts 2007). Again, the results were consistent with the findings we obtained using network density (Table 4, Models 4a and 4b).

Third, we estimated our model using different measures of sales performance (Table 4, Models 5a, 5b, 6a, and 6b). We began by using annual sales revenue (\$) instead of sales growth as the dependent variable. The results from the models were highly similar to those for sales growth as the dependent variable. Next, we used an annual measure of each RM's gross profit margin (\$) rather than sales growth. Again, this analysis produced a pattern of results similar to the one we obtained with sales growth as a dependent variable. The results from these alternative measures corresponded well with our final model (Model 2), which added to our confidence in the robustness of the theoretical underpinnings of our conceptual model.

\section{Discussion}

The effect of relationship marketing on performance has received widespread attention in the past two decades, though most research has focused on how to enhance firm performance by building relational ties with external exchange partners using a dyadic framework (Palmatier et al. 2006). Our study's findings suggest that researchers and managers should extend relationship marketing in two key ways - from an external to an internal perspective and from a dyadic to a network framework-by accounting for effects that occur across a web of intrafirm relational ties. Specifically, the structural sources of social capital, built within a firm's formal and informal networks, interact to drive RMs' sales performance. This study makes three theoretically and managerially important contributions to extant research. First, we advance social capital as a theoretical lens that marketing scholars can use to identify the intrafirm drivers of RMs' success, focused on the underlying mechanisms that drive information and cooperation advantages. Second, this study demonstrates that better-performing RMs leverage the social capital benefits they have gained from their informal network and combine them with social capital benefits from their formal network. Third, we show how overlap between formal and informal networks serves to enhance the positive effects of RM's intrafirm social capital. We discuss our findings in parallel with these three contributions.

\section{RMs' Intrafirm Social Capital}

Marketing scholars recognize that effective relationship management by boundary-spanning employees requires access to nonredundant information about opportunities for creating customer value and relies on the cooperation of key intrafirm members who translate that knowledge into performance-enhancing activities (Plouffe and Barclay 2007; Steward et al. 2010). Social capital theory provides a unique perspective for isolating the mechanisms and sources of social capital that explain the positive effects of information and cooperation benefits on RM performance.

First, these mechanisms result from the social structures that RMs inhabit within a firm's network of employees. For example, the ability to access and broker nonredundant information across the firm, which is possible when an RM's network has many structural holes, is critical for RM performance. The ability to depend on the cooperation of densely connected ties with firm employees (a result of enforcement and third-party monitoring) helps RMs successfully solve problems and satisfy customers. Thus, managers should understand that relationship-marketing programs focused on improving relational ties between coworkers represent a strategically viable alternative to 


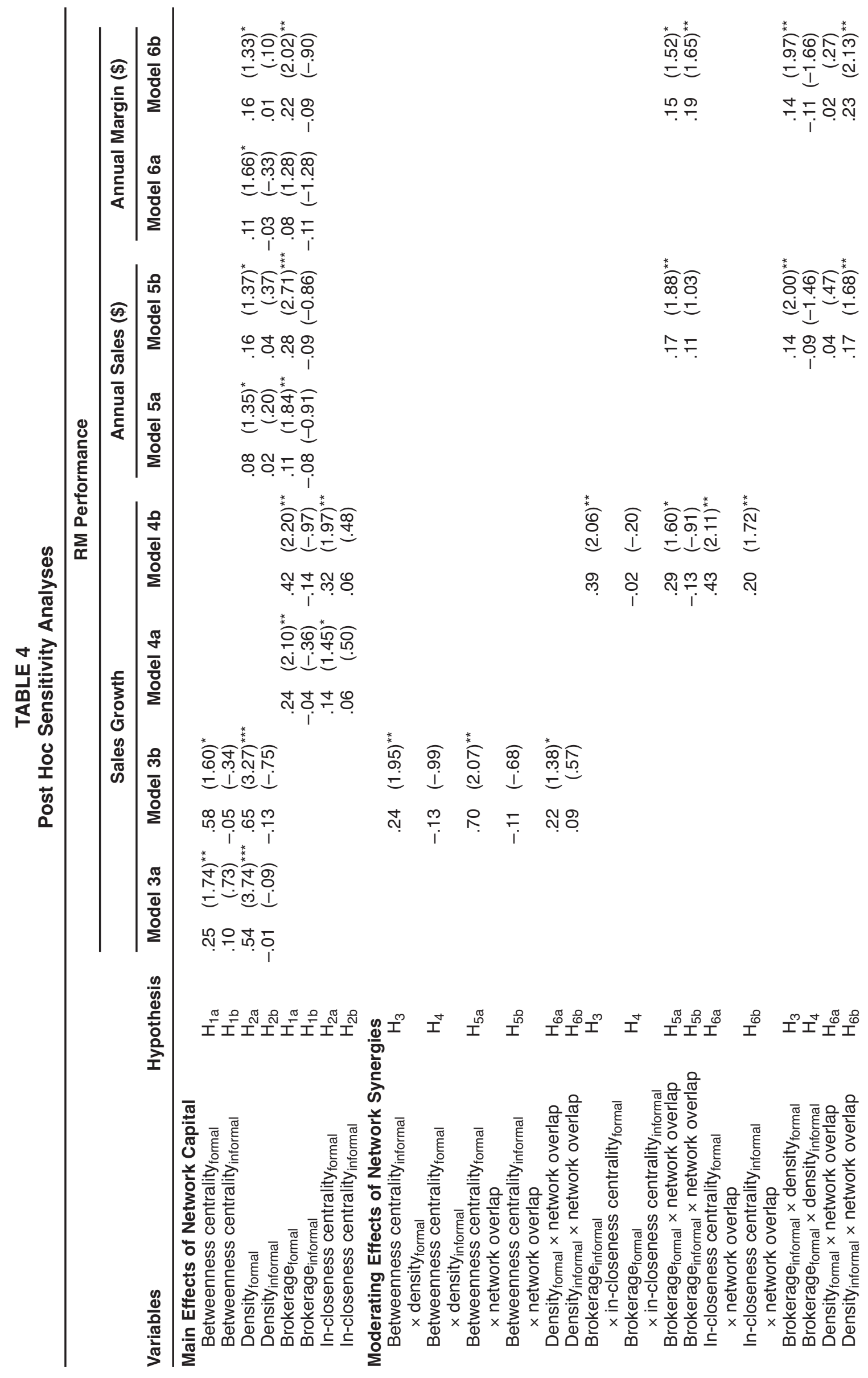




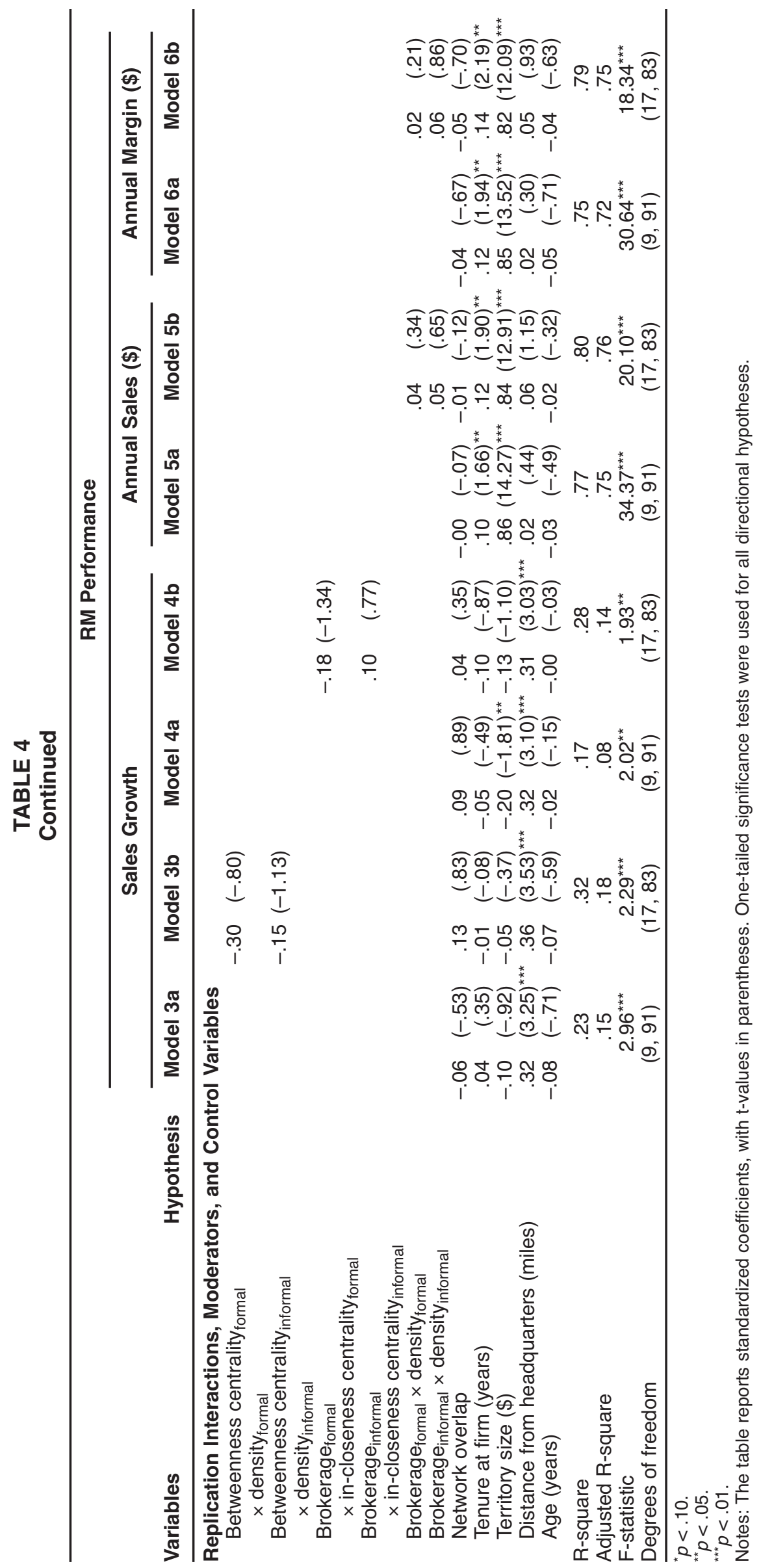


focusing solely on customer-centric relationship programs. Managers might reallocate some resources away from customer loyalty programs and toward internal employee relational programs to optimize their firms' overall performance, as Reichheld (2001) suggests.

Second, by providing insights into the relative importance of informal and formal networks for RM performance, our study is consistent with the social capital perspective, which indicates that different types of relations act as sources of different types of information and resources that people or firms exchange to achieve their objectives. Moreover, conclusions based on the effects of a single relationship or network can prove misleading because the synergies between networks are critical to understanding the "true" effect of intrafirm networks on performance. The finding that social capital measures had limited direct effects on performance might have arisen because RMs had relatively similar "levels" of social capital (e.g., similar formal networks) such that the "quality" of each RM's network had the greatest impact on performance. If we ignored network synergies and only evaluated the main effects of RM social capital, we might assume that informal networks have little effect on performance because the main effects were not significant in either model. However, our results show that RMs' informal network is critical for generating multiple types of network synergy, with significant effects on performance.

\section{Cross-Network Synergy}

Specific performance-enhancing effects of cross-network synergy are greater than the brokerage and density effects from a single network alone. These effects result when an RM combines information benefits gained from a widespread, nonredundant set of contacts in one network with a tightly woven set of ties in another network, which helps the RM act on the acquired information. The combination of brokerage in the informal network with density in the formal network positively affects RM performance. In a post hoc analysis using a median split, we found that RMs with above-average brokerage in their informal network achieved 27\% higher sales growth when they also enjoyed above-average (vs. below-average) density in their formal network, even though the informal network factors had no direct effect on performance. Evaluating RMs in the top and bottom quartiles, rather than through median splits, produced even stronger results: RMs in the top quartiles outperformed those in the bottom quartiles by $55 \%$.

In many ways, this brokerage $x$ density synergy parallels existing findings in management literature arguing that firms must develop and manage both exploration (search and discovery) and exploitation (execution and implementation) processes to adapt and thrive in competitive markets (March 1991). Boundary spanners with far-reaching and nonoverlapping informal networks (high structural holes) have well-developed search and discovery capabilities (exploration), but to meet their performance objectives, they need execution capabilities (exploitation), which they glean from a cooperative team of support contacts (high density). Further research could investigate what other insights might be derived from the application of cross-network explorationexploitation theoretical perspectives to relationship marketing contexts.

Cross-network synergy suggests that managers should encourage RMs to develop far-reaching and nonredundant informal ties (e.g., cross-functional meetings, rotating assignments) while also formally embedding RMs in densely connected support teams (e.g., hybrid or matrix RM organizational structure, colocation). Practitioners should institute a two-pronged approach: (1) create activities and incentives that lead members of disparate organizational areas to form informal ties and share information and (2) consider ways to embed RMs in dense networks to provide cooperative support rather than relying solely on cost or size considerations. Firms should also adopt a network perspective when restructuring their boundary-spanning units and developing new communication channels to enhance performance. The structure of intrafirm network ties can provide a competitive advantage with regard to managing customer relationships and growing sales if the resources gained from formal ties can be combined with those from informal ties.

\section{Overlap-Network Synergy}

Overlap-network synergy occurs when a network contact appears in both formal and informal networks, and this convergence enhances the effects of social capital benefits on RM performance. Our results suggest that it can occur in two ways. First, the ability to leverage nonredundant information accessed from the intrafirm network (both formal and informal networks) improves when more of the RM's immediate contacts represent overlapping ties who are more motivated to share unique and private information. Second, the positive effect of density on RM performance is enhanced when more of an RM's formal ties are informal ties as well. Our empirical results are consistent with Ross and Robertson's (2007) conceptual article, which argues for the importance of compound relationships, and with Tuli, Bharadwaj, and Kohli's (2010) results, which show a positive effect of multiple interfirm relational ties. The overall logic is similar: RMs are more effective when their formal support group consists of informal contacts (or vice versa) who are more relationally motivated to share information and cooperate fully.

Managers must understand the importance of network overlap and work to promote RMs' efforts to build interpersonal relationships with contacts in their formal support network (e.g., colocating RMs with support personnel, holding team-building and social events, developing congruent goals and compensation systems). Including internal relationship-building tools in RMs' training programs might prove effective. Such actions could have significant effects on RM performance. For example, for the three significant moderating effects of network overlap, we found that an increase in any RM's social capital measure by one standard deviation improved sales performance by $7 \%$ on average, whereas this same amount of improvement in social capital increased sales performance by $36 \%$ when accompanied by a high degree of network overlap. Thus, in our sample, 
RMs' social capital was 29 percentage points more effective for enhancing sales growth when combined with a high degree of overlap in their informal and formal networks.

From simple slope analyses, we note that with low network overlap (dashed line in Figure 4, Panel D), a highly dense informal network can be detrimental to performance. This relatively surprising finding is consistent with the perspective that insular, highly dense networks can create structural rigidity or cognitive inertia among their members, who develop similar thinking and attitudes. In such a network, few members think creatively, and some may ignore outside information; it may be difficult for them to do anything differently because their contacts are so closely connected that flexibility disappears (Gargiulo and Benassi 2000). Low overlap might aggravate this potential dark side of high density by reducing the number of outside viewpoints, because fewer network contacts span multiple networks as network overlap diminishes. Thus, building network overlaps may provide firms with a means to avoid structural rigidity and cognitive inertia among employees, which can be especially critical for anyone involved in the innovation process. Further research should explore this notable result to disentangle the performance benefits of network overlap that are due to positive relational motivational effects from those that are due to reduced negative structural rigidity and cognitive inertia effects.

\section{Limitations and Further Research}

This research context provides several important advantages for studying the social capital drivers of RM performance. The data pertaining to the whole network-a significant challenge for data collection efforts - enable tests of network-level hypotheses, and the single-firm research setting affords clearly delineated boundaries, fully enumerated populations, and rich and highly meaningful findings. However, this context also presents limitations, because the findings cannot be easily generalized across firms or industries. Although extant literature has implied that the underlying theoretical rationale holds across contexts, we need further testing to confirm such conclusions.

Additional research should also develop psychometric measures of network characteristics that support the investigation of social capital, without needing to capture complete network data. In focusing on distinct networks in which RMs may be members, we chose two prevalent networks. However, other networks based on different types of ties (e.g., advice, mentor) could have similar or distinct, direct and synergistic effects on performance. Moreover, future studies should assess the impact of ties to different functional areas. Are ties to certain functional domains more important to RM performance, and do certain network structures or positions within those functional areas lead to performance advantages? In addition, contacts that RMs maintain outside their firms may provide varied and novel information and perhaps even support in some situations (e.g., suppliers)

We model social capital as a positive driver of RM performance, though some scholars warn that social capital development creates risks (Gargiulo and Benassi 2000). The results point to some conditions in which social structures (e.g., dense informal networks) can hinder performance. For example, a lack of social capital in tightly knit groups might induce free riding. Further research should clarify this "dark side" of social capital for RM performance. Perhaps RMs whose networks are characterized by structural holes can manipulate information exchanges negatively because their contacts are relatively unconnected and unable to monitor all exchanges. Additional research should evaluate whether this strategy might be beneficial for the RM but damaging for the company as a whole. A single counterproductive member can negatively affect a dense network easily.

\section{REFERENCES}

Adler, Paul S. and Seok-Woo Kwon (2002), "Social Capital: Prospects for a New Concept," Academy of Management Review, 27 (1), 17-40.

Aiken, Leona and Stephen G. West (1991), Multiple Regression: Testing and Interpreting Interactions. Newbury Park, CA: Sage Publications.

Antia, Kersi D. and Gary L. Frazier (2001), "The Severity of Contract Enforcement in Interfirm Channel Relationships," Journal of Marketing, 65 (October), 67-81.

Beckman, Christine and Pamela R. Haunschild (2002), "Network Learning: The Effect of Partners' Heterogeneity of Experience on Corporate Acquisitions," Administrative Science Quarterly, 47 (1), 92-124.

Borgatti, Stephen P., Martin G. Everett, and Linton C. Freeman (2002), UCINET for Windows. Boston: Analytic Technologies.

Brass, Daniel J. (1984), "Being in the Right Place: A Structural Analysis of Individual Influence in an Organization," Administrative Science Quarterly, 29 (4), 518-39.
_ and Marlene E. Burckhardt (1993), "Potential Power and Power Use: An Investigation of Structure and Behavior," Academy of Management Journal, 36 (3), 441-70.

Burt, Ronald S. (1992), Structural Holes: The Social Structure of Competition. Cambridge, MA: Harvard University Press.

_ (1997), "The Contingent Value of Social Capital," Administrative Science Quarterly, 42 (2), 339-65.

(2004), "Structural Holes and Good Ideas," American Journal of Sociology, 110 (2), 349-99.

— (2005), Brokerage and Closure: An Introduction to Social Capital. Oxford, UK: Oxford University Press.

Coleman, James S. (1988), "Social Capital in the Creation of Human Capital," American Journal of Sociology, 94 (Supplement), S95-S120.

(1990), Foundations of Social Theory. Cambridge, MA: Harvard University Press.

Davies, Ian A., Lynette J. Ryals, and Sue Holt (2010), "Relationship Management: A Sales Role, or a State of Mind? An Investigation of Functions and Attitudes Across a Business-to-Business 
Sales Force," Industrial Marketing Management, 39 (7), 1049_ 62.

Freeman, Linton C. (1979), "Centrality in Social Networks: Conceptual Clarification," Social Networks, 1 (3), 215-39.

_ Stephen P. Borgatti, and Douglas R. White (1991), “Centrality in Valued Graphs: A Measure of Betweenness Based on Network Flow," Social Networks, 13 (2), 141-52.

Gargiulo, Martin and Mario Benassi (2000), "Trapped in Your Own Net? Network Cohesion, Structural Holes, and the Adaptation of Social Capital," Organization Science, 11 (2), 183-96.

Grönroos, Christian (1994), "From Marketing Mix to Relationship Marketing: Towards a Paradigm Shift in Marketing," Management Decisions, 32 (2), 4-20.

Hutt, Michael D., Peter H. Reingen, and John R. Ronchetto Jr. (1988), "Tracing Emergent Processes in Marketing Strategy Formation," Journal of Marketing, 52 (January), 4-19.

Ibarra, Herminia (1993), "Network Centrality, Power, and Innovation Involvement: Determinants of Technical and Administrative Roles," Academy of Management Journal, 36 (3), 471-501.

Joshi, Ashwin W. (2010), "Salesperson Influence on Product Development: Insights from a Study of Small Manufacturing Organizations," Journal of Marketing, 74 (January), 94-107.

Krackhardt, David (1990), “Assessing the Political Landscape: Structure, Cognition, and Power in Organizations," Administrative Science Quarterly, 35 (2), 342-69.

_ and Jeffrey R. Hanson (1993), "Informal Networks: The Company Behind the Chart," Harvard Business Review, 71 (4), 104-111.

— and Robert N. Stern (1988), "Informal Network and Organizational Crises: An Experimental Simulation," Social Psychology Quarterly, 51 (2), 123-40.

Lazega, Emmanuel and Phillipa E. Pattison (1999), "Multiplexity, Generalized Exchange, and Cooperation in Organizations: A Case Study," Social Networks, 21 (1), 67-90.

March, James G. (1991), "Exploration and Exploitation in Organizational Learning," Organizational Science, 2 (1), 71-87.

Mitchell, J. Clyde (1969), "The Concept and Use of Social Networks," in Social Networks in Urban Situations: Analysis of Personal Relationships in Central African Towns, J. Clyde Mitchell, ed. Manchester, UK: Manchester University Press, $1-50$.

Moran, Peter (2005), “Structural vs. Relational Embeddedness: Social Capital and Managerial Performance," Strategic Management Journal, 26 (12), 1129-51.

Palmatier, Robert W. (2008), "Interfirm Relational Drivers of Customer Value," Journal of Marketing, 72 (July), 76-89.

— , Rajiv P. Dant, Dhruv Grewal, and Kenneth R. Evans (2006), "Factors Influencing the Effectiveness of Relationship Marketing: A Meta-Analysis," Journal of Marketing, 70 (October), 136-53

—_ Lisa K. Scheer, and Jan-Benedict E.M. Steenkamp (2007), "Customer Loyalty to Whom? Managing the Benefits and Risks of Salesperson-Owned Loyalty," Journal of Marketing Research, 44 (May), 185-99.

Plouffe, Christopher R. and Donald W. Barclay (2007), "Salesperson Navigation: The Intraorganizational Dimension of the Sales Role," Industrial Marketing Management, 36 (4), 528 39.

Podolny, Joel M. and James N. Baron (1997), "Relationships and Resources: Social Networks and Mobility in the Workplace," American Sociological Review, 62 (5), 673-93.

Reagans, Ray and Bill McEvily (2003), "Network Structure and Knowledge Transfer: The Effects of Cohesion and Range," Administrative Science Quarterly, 48 (2), 240-67.
_ _ and Ezra W. Zuckerman (2001), "Networks, Diversity, and Productivity: The Social Capital of Corporate R\&D Teams," Organization Science, 12 (4), 502-517.

$\ldots, \ldots$, and Bill McEvily (2004), "How to Make the Team: Social Networks Versus Demography as Criteria for Designing Effective Teams," Administrative Science Quarterly, 49 (1), 101-133.

Rindfleisch, Aric and Christine Moorman (2001), "The Acquisition and Utilization of Information in New Product Alliances: A Strength-of-Ties Perspective," Journal of Marketing, 65 (April) 1-18.

— and (2003), "Interfirm Cooperation and Customer Orientation," Journal of Marketing Research, 40 (November), 421-36.

Reichheld, Frederick F. (2001), "Lead for Loyalty," Harvard Business Review, 79 (7), 76-84.

Ronchetto, John R., Jr., Michael D. Hutt, and Peter H. Reingen (1989), "Embedded Influence Patterns in Organizational Buying Systems," Journal of Marketing, 53 (October), 51-62.

Ross, William T. and Diana C. Robertson (2007), "Compound Relationships Between Firms," Journal of Marketing, 71 (July), 108-123.

Seevers, Mathew T., Steven J. Skinner, and Scott W. Kelley (2007), "A Social Network Perspective on Sales Force Ethics," Journal of Personal Selling and Sales Management, 27 (4), 341-53.

Sheth, Jagdish N. and Arun Sharma (2008), "The Impact of the Product to Service Shift in Industrial Markets and the Evolution of the Sales Organization," Industrial Marketing Management, 37 (3), 260-69.

Smith-Doerr, Laurel and Walter M. Powell (2005), "Networks and Economic Life," in The Handbook of Economic Sociology, Neil J. Smelser and Richard Swedberd, eds. Princeton, NJ: Princeton University Press, 379-402.

Sparrowe, Raymond T. and Robert C. Liden (2005), "Two Routes to Influence: Integrating Leader-Member Exchange and Social Network Perspectives," Administrative Science Quarterly, 50 (4), 505-535.

Stam, Wouter and Tom Elfring (2008), "Entrepreneurial Orientation and New Venture Performance: The Moderating Role of Intra- and Extraindustry Social Capital," Academy of Management Journal, 51 (1), 97-111.

Steward, Michelle D., Beth A. Walker, Michael D. Hutt, and Ajith Kumar (2010), "The Coordination Strategies of High-Performing Salespeople: Internal Working Relationships That Drive Success," Journal of the Academy of Marketing Science, 38 (5), 550-56.

Swaminathan, Vanitha and Christine Moorman (2009), "Marketing Alliance, Firm Networks, and Firm Value Creation," Journal of Marketing, 73 (September), 52-69.

Tsai, Wenpin and Sumantra Ghoshal (1998), "Social Capital and Value Creation: The Role of Intrafirm Networks," Academy of Management Journal, 41 (4), 464-76.

Tuli, Kapil R., Sundar G. Bharadwaj, and Ajay K. Kohli (2010), "Ties That Bind: The Impact of Multiple Types of Ties with a Customer on Sales Growth and Sales Volatility," Journal of Marketing Research, 47 (February), 36-50.

_—_ Ajay K. Kohli, and Sundar G. Bharadwaj (2007), "Rethinking Customer Solutions: From Product Bundles to Relational Processes," Journal of Marketing, 71 (July), 1-17.

Üstüner, Tuba and David Godes (2006), "Better Sales Networks," Harvard Business Review, 84 (7/8), 102-112.

Uzzi, Brian and Jarrett Spiro (2005), "Collaboration and Creativity: The Small World Problem," American Journal of Sociology, 111 (2), 447-504. 
Van den Bulte, Christophe and Stefan Wuyts (2007), Social Networks and Marketing. Cambridge, MA: Marketing Science Institute.

Weitz, Barton A. and Kevin D. Bradford (1999), "Personal Selling and Sales Management: A Relationship Marketing Perspective," Journal of the Academy of Marketing Science, 27 (2), 241-54.
Wuyts, Stefan, Stefan Stremersch, Christophe Van Den Bulte, and Philip Hans Franses (2004), "Vertical Marketing Systems for Complex Products: A Triadic Perspective," Journal of Marketing Research, 41 (November), 479-87. 
Copyright of Journal of Marketing is the property of American Marketing Association and its content may not be copied or emailed to multiple sites or posted to a listserv without the copyright holder's express written permission. However, users may print, download, or email articles for individual use. 